Check for updates

Cite this: Chem. Sci., 2018, 9, 6679

๑ All publication charges for this article have been paid for by the Royal Society of Chemistry

\section{Oxidative strong metal-support interactions (OMSI) of supported platinum-group metal catalysts $\uparrow$}

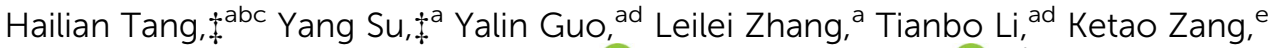

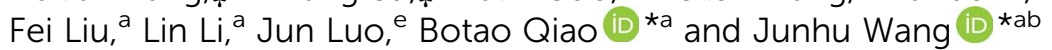

Supported platinum-group metal (PGM) catalysts are widely used in many important industrial processes. Metal-support interaction is of great importance in tailoring their catalytic performance. Here, we report the first example of oxidative strong metal-support interactions (OMSIs) between PGM and hydroxyapatite (HAP) which can be extended to PGM and ZnO. It occurred under high-temperature oxidation conditions accompanied by the encapsulation of PGM by HAP and electron transfer between PGM and HAP. With this OMSI, the aggregation and leaching of PGMs were significantly inhibited, resulting in an excellent catalytic stability and much improved reusability of supported $\mathrm{Pt}$ and $\mathrm{Pd}$ catalysts, respectively. This is the first time to find that PGMs can manifest OMSI which benefits the stabilization of PGM catalysts under oxidative reaction conditions. This new type of SMSI not only contributed to a deeper understanding of SMSI but also provided a new way to develop new stable PGM catalysts.

Received 26th March 2018

Accepted 10th July 2018

DOI: $10.1039 / \mathrm{c} 8 \mathrm{sc} 01392 \mathrm{f}$

rsc.li/chemical-science

\section{Introduction}

Platinum-group metals (PGMs) are widely used as catalysts in many commercial chemical processes such as automotive pollution control, petrochemical, pharmaceutical feedstocks and fuel cell power generation. ${ }^{\mathbf{1}}$ To use them more efficiently, PGMs were usually finely dispersed on high-surface-area materials (referred as support). The support can therefore influence the metals' catalytic performance through the metal-support interaction between them..$^{2-5}$ Specially, in the late 1970s Tauster and his co-workers observed a dramatic adsorption suppression of small molecules (such as CO and $\mathrm{H}_{2}$ ) over $\mathrm{TiO}_{2}$ supported PGMs after high-temperature reduction (HTR) and termed this phenomenon as strong metal-support interactions (SMSI). ${ }^{6,7}$ The discovery of SMSI triggered a hot research topic subsequently, ${ }^{7-12}$ owning to its

${ }^{a}$ State Key Laboratory of Catalysis, Dalian Institute of Chemical Physics, Chinese Academy of Sciences, Dalian 116023, China.E-mail: bqiao@dicp.ac.cn

${ }^{b}$ Mössbauer Effect Data Center, Dalian Institute of Chemical Physics, Chinese Academy of Sciences, Dalian 116023, China

${ }^{c}$ College of Chemistry and Environmental Science, Hebei University, Baoding 071002, China

${ }^{d}$ University of Chinese Academy of Sciences, Beijing 100049, China

${ }^{e}$ Center for Electron Microscopy, Institute for New Energy Materials and Low-Carbon Technologies, School of Materials, Tianjin University of Technology, Tianjin 300384, China

$\dagger$ Electronic supplementary information (ESI) available: Experimental Section, Fig. S1-S12 and Table S1. See DOI: 10.1039/c8sc01392f

\$ These authors contributed equally to this work. significant influence on the structure and electric property of PGM catalysts and their catalytic performance., ${ }^{7,9,10}$ However, so far all studies concerning SMSI on PGM catalysts are focused on those occurred upon HTR; whether SMSI can occurred upon high-temperature oxidation (HTO) treatment remains undiscovered.

Recently the topic of SMSI has re-attracted extensive interests, primarily due to discoveries ${ }^{13-17}$ on some new types of SMSI as well as their applications. ${ }^{18-20}$ For example, a new type of SMSI, i.e., HTO induced SMSI (referred as oxidative SMSI and denoted as OMSI hereafter) was found to occur between $\mathrm{Au}$ and ZnO-nanorod ${ }^{\mathbf{1 3}}$ and $\mathrm{Au}$ and hydroxyapatite (HAP). ${ }^{\mathbf{1 4}}$ The occurrence of OMSI was initially ascribed to the special property of $\mathrm{Au}$ that is different from that of PGMs because for a long time $\mathrm{Au}$ has not been found to manifest SMSI with $\mathrm{TiO}_{2}$. However, last year we discovered that the SMSI can indeed occur between $\mathrm{Au}$ and $\mathrm{TiO}_{2}$ with appropriate $\mathrm{H}_{2}$-treatments. ${ }^{15}$ This new finding suggested that there may be no intrinsic difference between $\mathrm{Au}$ and PGMs in manifesting SMSI, which in turn imply that PGMs may also manifest OMSI on suitable support and with appropriate treatments. If the latter is true, it would be highly significant in fundamental study because for decades people have believed that the HTR procedure is the prerequisite to the occurrence of SMSI. ${ }^{7,8,21}$ The occurrence of OMSI between PGM and supports can therefore change this viewpoint and make people re-recognize and re-understand the SMSI phenomenon and formation mechanism. Of more importance, the OMSI of PGMs would be very valuable in practical applications given that they are in many cases industrially used in oxidative conditions. 
For instance, automotive pollution control is one of the most important application areas of PGMs as more than half of the annually produced PGMs were consumed in preparing threeway catalysts (TWCs). ${ }^{22,23}$ The sintering of PGMs is still the major issue in regard to the catalyst deactivation..$^{\mathbf{2 4 , 2 5}}$ The SMSI effect can effectively stabilize the metal NPs and promote the durability of the catalysts. ${ }^{\mathbf{1 4 , 1 5 , 2 0}}$ However, the stabilizing effect of the classical SMSI can, at least theoretically, not persist under HTO conditions (TWC's working condition) owning to the reverse of the $\mathrm{SMSI}^{\mathbf{2 6 , 2 7}}$ while the OMSI might works well at this condition. The topic of SMSI re-attracted extensive interests recently due to some new discoveries ${ }^{13-17}$ on SMSI as well as their new applications. ${ }^{18-20}$ A new type of SMSI, i.e., HTO induced SMSI (referred as oxidative SMSI and denoted as OMSI hereafter) between $\mathrm{Au}$ and $\mathrm{ZnO}$-nanorod ${ }^{\mathbf{1 3}}$ and $\mathrm{Au}$ and hydroxyapatite (HAP) ${ }^{\mathbf{1 4}}$ were recently discovered. This was initially considered to be due to the different properties of $\mathrm{Au}$ from those of PGMs because for a long time, Au has not been found to manifest $\mathrm{H}$-SMSI with $\mathrm{TiO}_{2}$. However, in the last year we discovered that the H-SMSI can indeed occur between Au and $\mathrm{TiO}_{2}$ with appropriate $\mathrm{H}_{2}$-treatments. ${ }^{15}$ This new finding suggested that there may be no intrinsic difference between $\mathrm{Au}$ and PGMs in manifesting SMSI, which may in turn imply that PGMs can also manifest OMSI suitable support and appropriate treatments. If the latter is true, it would be highly significant in the fundamental study because for decades people have been believing that the HTR procedure is the prerequisite for the occurrence of SMSI., ${ }^{7,8,21}$ The OMSI between PGM and supports can therefore change this viewpoint and make people rerecognize and re-understand the SMSI phenomenon and formation mechanism. Of more importance, the OMSI of PGMs would be very valuable in practical applications given that they are in many cases industrially used in oxidative conditions. For instance, automotive pollution control is one of the most important application areas of PGMs as more than half of the annually produced PGMs were consumed in preparing threeway catalysts (TWCs). ${ }^{22,23}$ The sintering of PGMs is still the major issue concerning the catalyst deactivation. ${ }^{24,25}$ The SMSI effect can effectively stabilize the metal NPs and promote the durability of the catalysts. ${ }^{\mathbf{1 4 , 1 5 , 2 0}}$ However, the stabilizing effect of the H-SMSI can, at least theoretically, not persist under HTO conditions (such as TWC's working conditions) owing to the reverse of the $\mathrm{SMSI}^{26,27}$ while the OMSI might work well at this condition.

In this work, we report our discovery that PGMs (Pd and Pt) can manifest OMSI with both HAP and the ZnO-nanorod support wherein the PGM NPs were encapsulated by the support thus the metal leaching and aggregation were effectively inhibited, resulting in an excellent reaction stability of Pt/ HAP in CO oxidation in a simulated practical application conditions and a much-improved reusability of Pd/HAP in Suzuki cross-coupling, a liquid phase reaction. This is the first time to discover that PGMs can form OMSI which not only contributed to a deeper understanding of the SMSI effect, but also provided a new way to fabricate stable PGM catalysts in diverse application conditions.

\section{Results and discussion}

\section{Preparation of HAP supported PGM catalysts}

The HAP was synthesized by a precipitation method ${ }^{28}$ and further calcined at $400{ }^{\circ} \mathrm{C}$ before used as a support. The Pd and Pt species were introduced onto the HAP by a facile adsorption $\operatorname{method}^{29,30}$ with metal loading of 0.22 and $0.61 \mathrm{wt} \%$, respectively, and denoted as Pd/HAP-fresh and Pt/HAP-fresh, respectively. The fresh samples were subsequently oxidized at $500{ }^{\circ} \mathrm{C}$ under $10 \mathrm{vol} \% \mathrm{O}_{2} / \mathrm{He}$ flow and denoted as M/HAP-O, where $\mathrm{M}$ represents Pd and Pt. For comparison, the samples of M/HAP-O were further reduced under $10 \mathrm{vol} \% \mathrm{H}_{2} / \mathrm{He}$ flow at 250 or $500{ }^{\circ} \mathrm{C}$ and denoted as M/HAP-OH. Details of the synthesis procedure of HAP, preparation methods and thermal treating protocols (Scheme S1 $\dagger$ ) of M/HAP samples are presented in the Experimental section in the ESI. $\dagger$

\section{Characterization of PGM dispersion}

The XRD patterns of the Pd/HAP and Pt/HAP samples are shown in Fig. S1 $\uparrow$. It shows that the patterns of both the series of catalysts are exactly the same as that of HAP; that is, no diffuse diffraction peaks of the supported metal or metal oxide phase were observed. This result suggested that either the Pd or Pt species are highly dispersed on the support of HAP under various redox treatments, demonstrating a good stability which is probably due to a strong interaction with the support, or the metal loading amount is too low to be detected by XRD. To confirm the high dispersion of Pd and Pt species, the samples were further examined by electron microscopy. Representative high-angle annular dark-field scanning transmission electron microscopy (HADDF-STEM) images of various Pd/HAP and Pt/ HAP samples are presented in Fig. S2 $\uparrow$. It reveals clearly that on all samples the Pd and Pt NPs are highly dispersed with a size of $<2 \mathrm{~nm}$.

\section{Identification of OMSI}

There are four basic characteristics concerning the SMSI, ${ }^{\mathbf{1 3 - 1 5}}$ i.e., (i) the significant suppression of small-molecule adsorption (such as $\mathrm{CO}$ and $\mathrm{H}_{2}$ ), (ii) electron transfer between metals and the support, (iii) mass transport from the support to form the encapsulation of metal NPs, and (iv) a reversal of the preceding. phenomena upon reversal treatment.
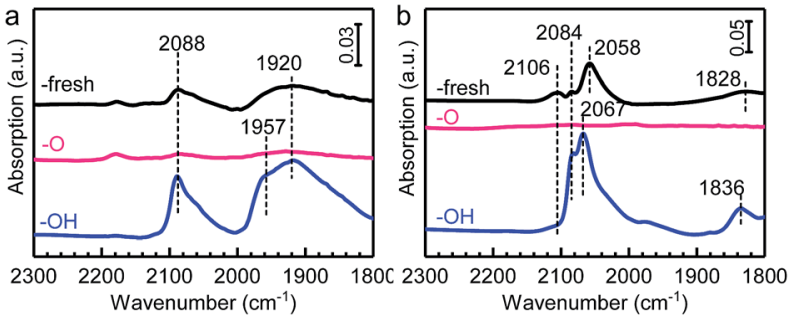

Fig. 1 In situ DRIFT spectra of CO adsorption on the (a) Pd/HAP and (b) $\mathrm{Pt} / \mathrm{HAP}$ series of samples obtained at $20^{\circ} \mathrm{C}$. Spectra were collected by purging gas $\mathrm{CO}$ with $\mathrm{He}$ after the samples were saturated by $\mathrm{CO}$ adsorption. 
The suppression of chemisorption of small molecules over these samples was firstly explored as it is the essential characteristic of SMSI. In situ diffuse reflectance infrared Fourier transform spectroscopy (DRIFTS) measurements were performed since it is sensitive to adsorption properties of the metal surface when an appropriate probe molecule was selected. ${ }^{31,32}$ As shown in Fig. 1a, for the sample of Pd/HAP-fresh, two peaks at 2088 and $1920 \mathrm{~cm}^{-1}$ were observed and attributed to linearand bridge-bonded $\mathrm{CO}$ on $\mathrm{Pd}$ species, respectively. ${ }^{33,34}$ However, no CO adsorption peak was observed for the sample of $\mathrm{Pd} / \mathrm{HAP}-\mathrm{O}$, suggesting a complete suppression of the adsorption after calcination with $10 \mathrm{v} \% \mathrm{O}_{2} / \mathrm{He}$ at elevated temperatures. It's worth noting that this suppression should not be, at least not majorly, caused by the oxidation of Pd, since $\mathrm{CO}$ adsorption can be detected on the oxidised Pd species. ${ }^{35,36}$ To confirm this, a control experiment on the Pd/HAP catalyst calcined at lower temperatures (300 and $400{ }^{\circ} \mathrm{C}$ ) under $10 \mathrm{v} \% \mathrm{O}_{2} / \mathrm{He}$ were performed and $\mathrm{CO}$ adsorption on oxidized Pd was clearly observed (as shown in Fig. S3†). Similar results were obtained on Pt/HAP samples, as shown in Fig. 1 b; the CO adsorption peaks on Pt species at 2106, 2084, 2058 and $1828 \mathrm{~cm}^{-1}$ over the Pt/HAPfresh sample, which were separately ascribed to linear $\mathrm{CO}$ adsorption on $\mathrm{PtO}_{x} \mathrm{NPs}, \mathrm{Pt}^{\delta+}$ single atoms, $\mathrm{Pt}^{0} \mathrm{NPs}$ and bridged $\mathrm{CO}$ adsorption on $\mathrm{Pt}$ species, ${ }^{37-40}$ were not observed after oxidation. This dramatic suppression of chemisorption on small metal NPs ( $<2 \mathrm{~nm}$, Fig. S2b and S2e $\dagger$ ) after HTO is identical to the feature that is observed on HAP supported Au NPs due to the physical coverage of the metal NPs surface by a thin layer of HAP. ${ }^{14}$ However, in this work it is difficult to directly verify the encapsulation layer by the high-resolution transmission electron microscopy (HRTEM) due to the ultrasmall metal NPs. We therefore performed a HTR treatment of the fresh samples at a higher temperature $\left(800{ }^{\circ} \mathrm{C}\right)$ with a longer time $(5 \mathrm{~h})$ before calcination to cause the aggregation of metal NPs. Then the reduced samples were subjected to the same calcination procedure and denoted as Pd/HAP-RO and Pt/HAP$\mathrm{RO}$, respectively. As expected, on these samples the size of some metal NPs increased significantly (Fig. S4†). Notably, the HRTEM images (Fig. 2) revealed clearly that both Pd and Pt NPs were covered by a thin layer, which should originated from the migration of HAP species onto them. ${ }^{14}$

One of the important characteristics of SMSI is that the above phenomena are reversible under the opposite treatment conditions. We therefore further reduced the calcined samples (M/HAP-OH) and measured their adsorption properties. As
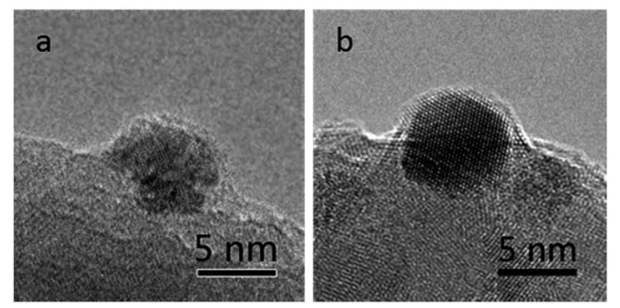

Fig. 2 HRTEM images of (a) Pd/HAP-RO and (b) Pt/HAP-RO samples which were treated under $10 \mathrm{v} \% \mathrm{H}_{2} / \mathrm{He}$ at $800{ }^{\circ} \mathrm{C}$ for $5 \mathrm{~h}$ followed by oxidation under $10 \mathrm{v} \% \mathrm{O}_{2} / \mathrm{He}$ at $500{ }^{\circ} \mathrm{C}$ for $3 \mathrm{~h}$.

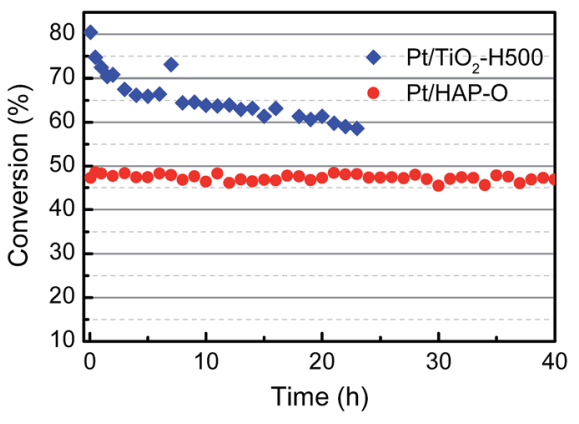

Fig. $3 \mathrm{CO}$ conversion curves as a function of reaction time on $\mathrm{Pt} /$ $\mathrm{HAP}-\mathrm{O}$ and $\mathrm{Pt} / \mathrm{TiO}_{2}-\mathrm{H} 500$ samples at $400{ }^{\circ} \mathrm{C}$. SV of Pt/HAP-O and Pt/ $\mathrm{TiO}_{2}-\mathrm{H} 500$ are $\sim 1690000$ and $1100000 \mathrm{~L} \mathrm{~g}_{\mathrm{Pt}}{ }^{-1} \mathrm{~h}^{-1}$, respectively. Reaction gas composition: $1.6 \mathrm{v} \% \mathrm{CO}, 1 \mathrm{v} \% \mathrm{O}_{2}, 0.01 \mathrm{v} \%$ propene, $0.0087 \mathrm{v} \%$ toluene, $10 \mathrm{v} \%$ water and balanced with $\mathrm{He}$.

shown in Fig. 1, the adsorption capacity was restored after reduction: On Pd/HAP-OH both adsorption peaks of linear-CO $\left(2088 \mathrm{~cm}^{-1}\right)$ and bridged-CO (1957 and $1920 \mathrm{~cm}^{-1}$ ) species were observed. On Pt/HAP-OH only three adsorption peaks at 2084, 2067 and $1836 \mathrm{~cm}^{-1}$ were clearly observed. The disappearance of the $2106 \mathrm{~cm}^{-1}$ peak suggested the reduction of $\mathrm{Pt}^{\delta+}$ NPs. The results clearly demonstrated a reversal of the adsorption capacity under redox treatments in our case, as this change is not owing to the dispersion change of the metals (Fig. S2 $\dagger$ ). The reversibility is exactly the same as that for the OMSI that occurred in the HAP supported Au catalyst. ${ }^{14}$

The occurrence of SMSI is usually accompanied by electron transfer between metal NPs and the support. The electronic properties of Pd and Pt under redox treatment were therefore examined by X-ray photoelectron spectroscopy (XPS). Unfortunately no effective information was obtained on the Pd/HAP sample due to the signal overlap of $\mathrm{Pd} 3 \mathrm{~d}$ and $\mathrm{Ca} 2 \mathrm{p}$. However, the XPS spectra of Pt suggested the reversible electron transfer clearly. As shown in Fig. S5 $\dagger$, the binding energy (BE) of Pt $2 \mathrm{p}_{3 / 2}$ in the Pt/HAP-fresh sample is $72.0 \mathrm{eV}$, suggesting that the $\mathrm{Pt}$ species existed in the $\mathrm{Pt}^{2+}$ oxidative state. The $\mathrm{BE}$ of $\mathrm{Pt}$ $2 \mathrm{p}_{3 / 2}$ shifted to $72.5 \mathrm{eV}$ after calcination at $500{ }^{\circ} \mathrm{C}$, suggesting that an electron transfer from Pt NPs to the HAP support occurred. After a subsequent $500{ }^{\circ} \mathrm{C}$-reduction treatment, the

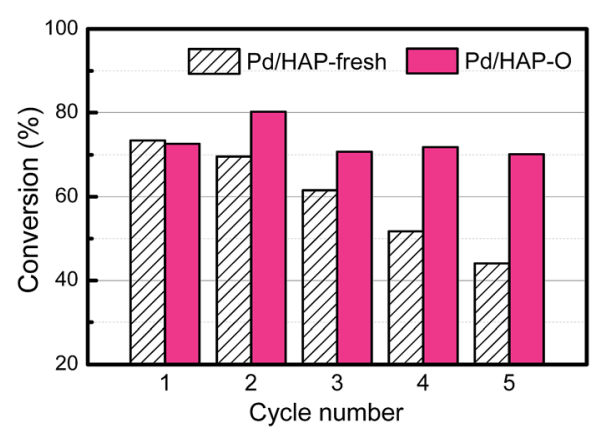

Fig. 4 Cycling performance of Pd/HAP-fresh and Pd/HAP-O in the Suzuki cross-coupling reaction. Reaction conditions: $80{ }^{\circ} \mathrm{C}, 3 \mathrm{~h}$, iodobenzene $(4 \mathrm{mmol})$, phenylboronic acid $(4.8 \mathrm{mmol}), \mathrm{K}_{2} \mathrm{CO}_{3}(8$ $\mathrm{mmol}), \mathrm{H}_{2} \mathrm{O}(20 \mathrm{~mL})$, and catalyst (50 mg). 

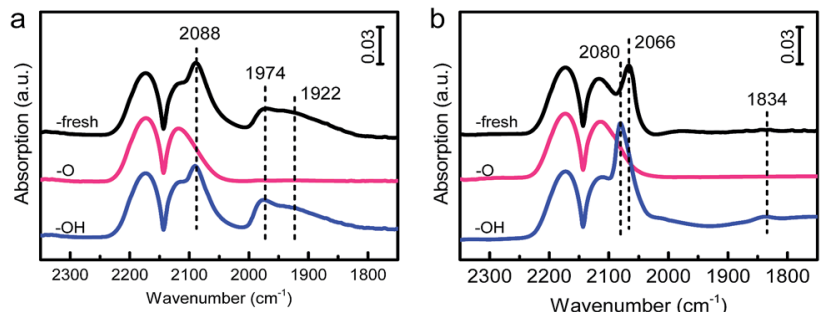

Fig. 5 In situ DRIFT spectra of $\mathrm{CO}$ adsorption on the (a) $\mathrm{Pd} / \mathrm{ZnO}$ and (b) $\mathrm{Pt} / \mathrm{ZnO}$ series samples obtained at $20^{\circ} \mathrm{C}$.

$\mathrm{BE}$ of Pt $2 \mathrm{p}_{3 / 2}$ shifted to $71.0 \mathrm{eV}$, the typical value for metallic Pt. This reversibility of the electron transfer under redox treatments in the Pt/HAP sample is exactly the same as that for the OMSI that occurred on the HAP supported Au catalyst. ${ }^{14}$ It should be noted that the absence of the $\mathrm{Pt}^{0}$ species in the $\mathrm{Pt} /$ HAP-fresh sample detected by XPS seems discrepant with the DRIFTS results where a peak of $\mathrm{CO}-\mathrm{Pt}^{0}$ at $2058 \mathrm{~cm}^{-1}$ was observed (Fig. 1b). This can be explained by the in situ reduction of the partial surface $\mathrm{Pt}^{2+}$ species during the CO adsorption measurements. ${ }^{20,41}$

The above results unambiguously demonstrated the occurrence of OMSI between PGMs and HAP, a kind of nonoxide. In our previous work, we have proven that Au can form OMSI with HAP and we proposed that the occurrence of this OMSI is related to the change of the $\mathrm{PO}_{4}{ }^{3-}$ species (cation didn't affect the occurrence of this SMSI) in an $\mathrm{O}_{2}$ atmosphere (in the inert gas this SMSI didn't occur).${ }^{14}$ However, recently, Xiao and coworkers found that on the $\mathrm{Mg}-\mathrm{Al}$ layered double oxides supported Au catalyst, Au NPs could be encapsulated by the support due to the hydroxide-to-oxide transformation under calcination, although this process is not reversible. ${ }^{17}$ This report together with the fact that HAP also contains the hydroxyl group $(-\mathrm{OH})$ inspired us to conjecture that the dehydroxylation during the calcination process may also contribute to the occurrence of this OMSI in the HAP system. If this is the case, a hydroxyl compensation may reverse the OMSI. To verify this, we treated the sample of Pd/HAP-O under $3 \mathrm{v} \% \mathrm{H}_{2} \mathrm{O} / \mathrm{He}$ at $250{ }^{\circ} \mathrm{C}$ for $0.5 \mathrm{~h}$ (denoted as $\mathrm{Pd} / \mathrm{HAP}-\mathrm{O}-\mathrm{H}_{2} \mathrm{O}$ ) and examined the $\mathrm{CO}$ adsorption by DRIFT. It was clearly observed that the CO adsorption on Pd restored compared with that treated by $\mathrm{O}_{2}$ (Fig. S6 $\dagger$ ), indicating that the $-\mathrm{OH}$ indeed plays an important role in the reverse of OMSI upon the HAP system. Accordingly, we believe that the dehydroxylation/dehydration may also trigger the OMSI. We therefore treated the sample in an inert gas (helium) at $500{ }^{\circ} \mathrm{C}$. It was found that $\mathrm{CO}$ adsorption didn't decrease at all, consistent with our previous result of Au/HAP. ${ }^{14}$ However, when treating the sample at a higher temperature $\left(800{ }^{\circ} \mathrm{C}\right.$, denoted as $\mathrm{Pd} / \mathrm{HAP}-\mathrm{He}-800$ ) where the dehydroxylation of HAP starts, ${ }^{42}$ a complete disappearance of $\mathrm{CO}$ adsorption was observed. As most of Pd NPs is in size $<5 \mathrm{~nm}$ (Fig. S7a and $\mathrm{b}_{\dagger}^{\dagger}$ ), this CO suppression should have been mainly due to the occurrence of OMSI rather than the increased Pd NP size. This was further confirmed by the HRTEM images. As suggested in Fig. S7c and $\mathrm{d}, \dagger$ the Pd NPs on the Pd/HAP-He-800 sample were encapsulated by a thin layer. We therefore further treated the Au/HAP sample in $\mathrm{He}$ at $800{ }^{\circ} \mathrm{C}$ (denoted as Au/HAP-He-800) and examined the CO adsorption by DRIFT. However, as shown in Fig. S8, $\dagger$ a peak at $2103 \mathrm{~cm}^{-1}$, ascribed to linear CO adsorption on metallic Au NPs, was clearly observed, demonstrating that a complete encapsulation of the Au NPs by HAP didn't occur. This is different from the Pd/HAP-He-800 sample which might originate from the different work function and surface energy of $\mathrm{Au}$ and PGMs. HRTEM images revealed that the Au NPs were actually partially encapsulated (Fig. S9†), in consistent with the DRIFT results. This set of experiments clearly demonstrated that the dehydroxylation/dehydration during high-temperature treatments contributes, at least partially, to the formation of OMSI. Of course, the contribution of the change of the $\mathrm{PO}_{4}{ }^{3-}$ species under an $\mathrm{O}_{2}$ atmosphere cannot be excluded. A detailed and systemic study is still needed to clarify the origin and mechanism of the OMSI.

\section{Catalytic performance}

The finding of OMSI of PGMs is of great value in practical application. For example, TWCs, consuming over half of annual PGM production, generally work in an oxidative atmosphere at elvated temperatures which requires the catalysts to be stable at HTO conditions. Our sample M/HAP-O, with the encapsulation occurring at HTO conditions, may meet this requirement. To verify this, we tested the durability of Pt/HAP-fresh and Pt/HAP$\mathrm{O}$ (with a Pt loading of $\sim 0.04 \mathrm{wt} \%$ that is in a similar level to the commercial TWCs to avoid activity saturation at higher temperatures) at $400{ }^{\circ} \mathrm{C}$ by using $\mathrm{CO}$ oxidation in a simulated auto-emission control as the probe reaction. ${ }^{20}$ As shown in Fig. S11 $\uparrow$, for the Pt/HAP-O sample, the conversion kept unchanged during a 40 hour test, showing an excellent stability. However, the Pt/HAP-fresh, as expected, showed a much higher initial CO activity but a much lower CO stability in the identical condition. The abrupt decrease of CO conversion at the $5^{\text {th }}$ hour should be ascribed to the formation of OMSI under the reaction conditions where a net oxidative gas atmosphere was remained after CO being totally converted. For comparison, we also tested a $\mathrm{Pt} / \mathrm{TiO}_{2}-\mathrm{H} 500$ catalyst prepared by the same method with a similar Pt loading. Before the test the sample was pre-reduced at $500{ }^{\circ} \mathrm{C}$ under $10 \mathrm{v} \% \mathrm{H}_{2} / \mathrm{He}$ for $1 \mathrm{~h}$ which would lead to the formation of classical SMSI. As shown in Fig. 3, although a higher initial CO conversion was obtained which should be due to the lower space velocity, the CO conversion decreased severely within a $23 \mathrm{~h}$ test, suggesting a much worse stability. This tendency is more straightforward when the result was presented in a reaction rate $v s$. reaction time model. As shown in Fig. $\mathrm{S} 12 \uparrow$, the $\mathrm{Pt} / \mathrm{TiO}_{2}-\mathrm{H} 500$ sample had slightly higher initial reaction rate $\left(\sim 630 \mathrm{~mol}_{\mathrm{CO}} \mathrm{g}_{\mathrm{Pt}}{ }^{-1} \mathrm{~h}^{-1}\right)$ compared with $\mathrm{Pt} / \mathrm{HAP}-\mathrm{O}$ $\left(\sim 570\right.$ mol $\left._{\mathrm{CO}} \mathrm{g}_{\mathrm{Pt}}{ }^{-1} \mathrm{~h}^{-1}\right)$ but deactivated quickly. On the contrary, the Pt/HAP-O catalyst is very stable and its reaction rate remained unchanged. The result of stalbity test clearly highlights the advantage of OMSI in this application.

In addition, PGM catalysts are widely used in fine chemical syntheses. They, however, suffer from the deactivation by metal leaching and aggregation during reaction. ${ }^{\mathbf{4 3 4}}$ Our previous work has demonstrated that the formation of OMSI 
can effectively inhibit the aggregation and leaching of Au NPs in the liquid phase alcohol oxidation reaction. ${ }^{14}$ In this work, this effect was further exemplified by using Suzuki crosscoupling, a widely used reaction in the organic synthesis industry catalyzed by Pd-based catalysts. ${ }^{45,46}$ As shown in Fig. 4, on the Pd/HAP-fresh sample the initial conversion of iodobenzene is $92 \%$. However, it continuously decreased to $50 \%$ in the subsequent 4 cycles. The analysis of the used catalyst shows that there is a severe leaching of Pd, with the Pd loading amount decreased from $0.36 \mathrm{wt} \%$ to $0.06 \mathrm{wt} \%$ (Table $\mathrm{S} 1 \dagger)$. Furthermore, besides a small amount of Pd NPs with a size of $\sim 2 \mathrm{~nm}$, some big Pd NPs can also be observed in the HAADF-STEM images (Fig. S10a and $b \dagger$ ), suggesting the aggregation of the Pd species during the reaction progress. On the contrary, the conversion $(\sim 90 \%)$ on the Pd/HAP-O kept almost unchanged in five cycle tests, suggesting an excellent reusability. As expected, after the reaction, the Pd NPs are still small $(\sim 2 \mathrm{~nm}$, Fig. S10c and $\mathrm{d} \dagger)$ and the Pd loading is $0.35 \mathrm{wt} \%$ (Table S1†), suggesting that the encapsulation layer can effectively prevent the leaching and aggregation of metal NPs, thus significantly enhance the reusability of the catalysts.

\section{OMSI in ZnO supported PGM catalysts}

It was also found previously that $\mathrm{Au}$ NPs can manifest OMSI with a ZnO-nanorod support. ${ }^{13}$ We therefore speculated that the OMSI can also occur upon the PGMs/ZnO system. To verify this, we further prepared ZnO-nanorod supported Pd and Pt samples and measured their CO adsorption properties by DRIFTS, and the results are presented in Fig. 5. Similar to that of $\mathrm{CO}$ adsorption on HAP supported catalysts, a reversible CO adsorption was detected on both the $\mathrm{Pd} / \mathrm{ZnO}$ and $\mathrm{Pt} / \mathrm{ZnO}$ samples, demonstrating the occurrence of OMSI.

\section{Conclusions}

In summary, in this work the OMSI $\left(\mathrm{O}_{2}\right.$-induced SMSI) between PGM NPs and HAP was discovered for the first time. It takes place with HTO and reversed with HTR. In addition, it also occurs at high-temperature treatment in inert gas atmosphere, and at least partially reversed with water treatment, suggesting that the losing of $-\mathrm{OH}$ group at high temperature partially contributes to the formation of OMSI. With this OMSI effect, the PGM NPs were encapsulated by a thin support layer thus their aggregation and leaching were effectively inhibited. As a result, the catalytic stability and the reusability of the M/HAP catalysts were significantly improved. Furthermore, it was found that this OMSI is general and can be extended to ZnO-nanorod supported PGM catalysts. The new findings in this work not only contributes to a deeper understanding of the SMSI effect but also would be beneficial for the development of ultrastable PGM catalysts in various application conditions, thus opening a new window for the design and tailor of PGM catalysts.

\section{Conflicts of interest}

There are no conflicts to declare.

\section{Acknowledgements}

This work was supported by National Key R\&D Program of China (2016YFA0202804), the Strategic Priority Research Program of the Chinese Academy of Science (XDB17020100), the National Natural Science Foundation of China (21776270, 21476232) and the Department of Science and Technology of Liaoning Province (2015020086-101).

\section{Notes and references}

1 R. J. Seymour and J. I. O'Farrelly, Platinum-Group Metals. KirkOthmer Encyclopedia of Chemical Technology, John Wiley \& Sons, 2001.

2 G.-M. Schwab, in Adv Catal, ed. H. P. D. D. Eley and B. W. Paul, Academic Press, 1979, vol. 27, pp. 1-22.

3 J. Liu, ChemCatChem, 2011, 3, 934-948.

4 H. Yi, Y. Xia, H. Yan and J. Lu, Chin. J. Catal., 2017, 38, 15811587.

5 H. Yang, J. Deng, Y. Liu, S. Xie, P. Xu and H. Dai, Chin. J. Catal., 2016, 37, 934-946.

6 S. J. Tauster, S. C. Fung and R. L. Garten, J. Am. Chem. Soc., 1978, 100, 170-175.

7 S. J. Tauster, Acc. Chem. Res., 1987, 20, 389-394.

8 S. J. Tauster and S. C. Fung, J. Catal., 1978, 55, 29-35.

9 R. T. K. Baker, E. B. Prestridge and R. L. Garten, J. Catal., 1979, 56, 390-406.

10 S. J. Tauster, S. C. Fung, R. T. K. Baker and J. A. Horsle, Science, 1981, 211, 1120-1125.

11 A. D. Logan, E. J. Braunschweig and A. K. Datye, Langmuir, 1988, 4, 827-830.

12 J. P. Belzunegui, J. Sanz and J. M. Rojo, J. Am. Chem. Soc., 1992, 114, 6749-6754.

13 X. Liu, M.-H. Liu, Y.-C. Luo, C.-Y. Mou, S. D. Lin, H. Cheng, J.-M. Chen, J.-F. Lee and T.-S. Lin, J. Am. Chem. Soc., 2012, 134, 10251-10258.

14 H. Tang, J. Wei, F. Liu, B. Qiao, X. Pan, L. Li, J. Liu, J. Wang and T. Zhang, J. Am. Chem. Soc., 2016, 138, 56-59.

15 H. Tang, Y. Su, B. Zhang, A. F. Lee, M. A. Isaacs, K. Wilson, L. Li, Y. Ren, J. Huang, M. Haruta, B. Qiao, X. Liu, C. Jin, D. Su, J. Wang and T. Zhang, Sci. Adv., 2017, 3, e1700231.

16 J. C. Matsubu, S. Zhang, L. DeRita, N. S. Marinkovic, J. G. Chen, G. W. Graham, X. Pan and P. Christophe, Nat. Chem., 2017, 9, 120-127.

17 L. Wang, J. Zhang, Y. Zhu, S. Xu, C. Wang, C. Bian, X. Meng and F.-S. Xiao, ACS Catal., 2017, 7, 7461-7465.

18 A. Corma, S. Pedro, C. Patricia and C. J. Juan, J. Am. Chem. Soc., 2008, 130, 8748-8753.

19 P. Sonström, D. Arndt, X. Wang, V. Zielasek and M. Bäumer, Angew. Chem., Int. Ed., 2011, 50, 3888-3891.

20 H. Tang, F. Liu, J. Wei, B. Qiao, K. Zhao, Y. Su, C. Jin, L. Li, J. J. Liu, J. Wang and T. Zhang, Angew. Chem., Int. Ed., 2016, 55, 10606-10611.

21 G. L. Haller and D. E. Resasco, Adv. Catal., 1989, 36, 173-235. 22 H. E. Hilliard, U.S. GEOLOGICAL SURVEY MINERALS YEARBOOK, 2002. 
23 Y. Zhang, R. W. Cattrall, I. D. McKelvie and S. D. Kolev, Gold Bull., 2011, 44, 145-153.

24 H. Shinjoh, Catal. Surv. Asia, 2009, 13, 184-190.

25 J.-J. He, C.-X. Wang, T.-T. Zheng and Y.-K. Zhao, Johnson Matthey Technol. Rev., 2016, 60, 196-203.

26 E. J. Braunschweig, A. D. Logan, A. K. Datye and D. J. Smith, J. Catal., 1989, 118, 227-237.

27 S. Bernal, F. J. Botana, J. J. Calvino, C. López, J. A. Pérez-Omil and J. M. Rodríguez-Izquierdo, J. Chem. Soc., Faraday Trans., 1996, 92, 2799-2809.

28 K. Zhao, B. Qiao, J. Wang, Y. Zhang and T. Zhang, Chem. Commun., 2011, 47, 1779-1781.

29 B. Qiao, J.-X. Liang, A. Wang, C.-Q. Xu, J. Li, T. Zhang and J. J. Liu, Nano Res., 2015, 8, 2913-2924.

30 R. Lang, T. Li, D. Matsumura, S. Miao, Y. Ren, Y. T. Cui, Y. Tan, B. Qiao, L. Li, A. Wang, X. Wang and T. Zhang, Angew. Chem., Int. Ed., 2016, 55, 16054-16058.

31 C. Lamberti, A. Zecchina, E. Groppo and S. Bordiga, Chem. Soc. Rev., 2010, 39, 4951-5001.

32 A. Vimont, F. Thibault-Starzyk and M. Daturi, Chem. Soc. Rev., 2010, 39, 4928-4950.

33 M. Fernández-García, A. Martínez-Arias, A. Iglesias-Juez, A. B. Hungría, J. A. Anderson, J. C. Conesa and J. Soria, Appl. Catal., B, 2001, 31, 39-50.
34 B. Qiao, J. Lin, L. Li, A. Wang, J. Liu and T. Zhang, ChemCatChem, 2014, 6, 547-554.

35 K. I. Hadjiivanov and G. N. Vayssilov, Adv. Catal., 2002, 47, 307-511.

36 D. Tessier, A. Rakai and F. Bozon-Verduraz, J. Chem. Soc., Faraday Trans., 1992, 88, 741-749.

37 P. Panagiotopoulou and D. I. Kondarides, J. Catal., 2008, 260, 141-149.

38 B. Qiao, A. Wang, X. Yang, L. F. Allard, Z. Jiang, Y. Cui, J. Liu, J. Li and T. Zhang, Nat. Commun., 2011, 3, 634-641.

39 M. J. Kale and P. Christopher, ACS Catal., 2016, 6, 55995609.

40 T. Avanesian, S. Dai, M. J. Kale, G. W. Graham, X. Pan and P. Christopher, J. Am. Chem. Soc., 2017, 139, 4551-4558.

41 K. Zhao, H. Tang, B. Qiao, L. Li and J. Wang, ACS Catal., 2015, 5, 3528-3539.

42 Y. Liu and Z. Shen, J. Eur. Ceram. Soc., 2012, 32, 2691-2696.

43 A. Biffis, M. Zecca and M. Basato, J. Mol. Catal. A: Chem., 2001, 173, 249-274.

44 L. D. Pachón and G. Rothenberg, Appl. Organomet. Chem., 2008, 22, 288-299.

45 N. Miyaura and A. Suzuki, Chem. Rev., 1995, 95, 2457-2483. 46 A. Suzuki, J. Organomet. Chem., 1999, 576, 147-168. 